\title{
LIVER
}

\section{Increased DMTI but not IREG1 or HFE mRNA following iron depletion therapy in hereditary haemochromatosis}

\author{
T Kelleher, E Ryan, S Barrett, M Sweeney, V Byrnes, C O'Keane, J Crowe
}

Gut 2004;53:1174-1179. doi: 10.1136/gut.2003.033811

See end of article for authors' affiliations .....................

Correspondence to: Dr J Crowe, Centre for Liver Disease, Mater Misericordiae University Hospital, Dublin 7, Ireland; liver@mater.ie

Revised version received 23 January 2004 Accepted for publication 14 February 2004 Background and aims: While upregulation of divalent metal transporter 1 (DMT1) and iron regulated
gene 1 (IREG1) within duodenal enterocytes is reported in patients with hereditary haemochromatosis $(\mathrm{HH})$, these findings are controversial. Furthermore, the effect of HFE, the gene mutated in $\mathrm{HH}$, on expression of these molecules is unclear. This study examines duodenal expression of these three molecules in $\mathrm{HH}$ patients (prior to and following phlebotomy), in patients with iron deficiency (ID), and in controls. Methods: DMT1, IREG1, and HFE mRNA were measured in duodenal tissue of C282Y homozygous $\mathrm{HH}$ patients, in ID patients negative for the C282Y mutation with a serum ferritin concentration less than $20 \mu \mathrm{g} / \mathrm{l}$, and in controls negative for $\mathrm{C} 282 \mathrm{Y}$ and H63D mutations with normal iron indices, using real time polymerase chain reaction.

Results: DMT1 and IREG1 mRNA levels were not significantly different in non-phlebotomised (untreated) $\mathrm{HH}$ patients compared with controls. DMT1 expression was significantly increased in $\mathrm{HH}$ patients who had undergone phlebotomy therapy (treated) and in patients with ID compared with controls. IREGI was significantly increased in ID patients relative to controls, and while IREG1 expression was 1.8-fold greater in treated $\mathrm{HH}$ patients, this was not statistically significant. HFE mRNA expression was not significantly different in any of the groups investigated relative to controls.

Conclusions: These findings demonstrate that untreated $\mathrm{HH}$ patients do not have increased duodenal DMTI and IREG mRNA, but rather phlebotomy increases expression of these molecules, reflecting the effect of phlebotomy induced erythropoiesis. Finally, HFE appears to play a minor role in the regulation of iron absorption by the duodenal enterocyte. lev ron absorption is regulated by several factors, including the level of body iron stores (via the stores regulator), the rate of erythropoiesis (via the erythroid regulator), and hypoxia. ${ }^{1-4}$ Although, the capacity of the stores regulator to alter iron absorption is low relative to the erythroid regulator, its function is critical for normal iron homeostasis, as demonstrated from findings in hereditary haemochromatosis $(\mathrm{HH})$. $\mathrm{HH}$ patients, the majority of whom $(>90 \%)$ are homozygous for a single missense mutation (C282Y) in the HFE gene, absorb excessive amounts of iron from the diet relative to body iron stores, indicating that the set point for the stores regulator may be changed. ${ }^{56}$

The stores and erythroid regulators reflect body iron requirements and determine the rate at which iron is absorbed by the duodenum through regulation of expression of several key proteins in the mature enterocytes of the duodenum, including divalent metal transporter l (DMTl), a transmembrane protein that actively transports reduced dietary iron into intestinal enterocytes, and iron regulated gene l (IREGl), a second transmembrane protein that is the putative exporter of iron through the basolateral membrane to plasma..$^{7-12}$

The manner in which the stores and erythroid regulators affect expression of these iron transport molecules is not clear but a link between body iron requirements and iron transport expression in the duodenum has been made with the identification of hepcidin, thought to be the predominant negative regulator of iron absorption. ${ }^{13-15}$

Relatively few studies have examined iron transporter expression in human $\mathrm{HH}$ subjects, and results are conflicting. The source of this conflict appears to arise primarily from inclusion of $\mathrm{HH}$ patients who have undergone phlebotomy therapy that per se causes significant increases in iron absorption. ${ }^{16-18}$ More recently, studies in untreated $\mathrm{HH}$ patients also demonstrated conflicting results. ${ }^{19} 20$ Furthermore, similar inconsistencies have also been observed in studies investigating mouse models of $\mathrm{HH}^{21-25}$

Little is known of the role of wild-type HFE in iron absorption and in maintenance of normal iron homeostasis which has hindered progress in elucidating how mutations in the HFE gene lead to inappropriate iron absorption in human subjects with $\mathrm{HH}^{26}$ Consequently, the effect of HFE on expression of iron transport molecules is unclear, although animal studies indicate that its role may be limited as HFE deficient mice retain the ability to regulate iron absorption. ${ }^{27} 28$

Here, we present our findings of expression of DMTl, IREGl, and HFE mRNA levels from a large cohort of untreated and treated $\mathrm{HH}$ patients, iron deficiency (ID) subjects, and normal controls.

\section{MATERIALS AND METHODS \\ Patients}

Duodenal biopsies were obtained from 52 individuals during upper gastrointestinal endoscopy. Biopsies were snap frozen in liquid nitrogen or stored in Qiagen RNAlater medium (Qiagen Ltd, UK). Simultaneously, all individuals had blood drawn for determination of fasting serum iron, serum ferritin $(\mathrm{SF})$, transferrin saturation (TS), haemoglobin $(\mathrm{Hb})$, and HFE genotyping. ${ }^{18}$

All $\mathrm{HH}$ patients $(\mathrm{n}=33)$ were diagnosed on the basis of homozygosity for the C282Y HFE mutation and persistently raised iron indices, defined as $S F \geqslant 200 \mu \mathrm{g} / \mathrm{l}$ for females and

Abbreviations: DMT1, divalent metal transporter 1; IREG1, iron regulated gene 1 ; $\mathrm{SF}$, serum ferritin; $\mathrm{TS}$, transferrin saturation; $\mathrm{Hb}$, haemoglobin; $\mathrm{HH}$, hereditary haemochromatosis; ID, iron deficiency; $\mathrm{PCR}$, polymerase chain reaction 
$\mathrm{SF} \geqslant 300 \mu \mathrm{g} / \mathrm{l}$ for males. All $\mathrm{HH}$ patients underwent endoscopy as part of varices screening or volunteered as part of the study protocol following full informed consent. The untreated HH group $(n=21)$ had biopsies taken prior to initiation of phlebotomy therapy. The treated HH group $(n=12)$ had biopsies taken following phlebotomy and these subjects did not include any of the untreated HH group who subsequently underwent phlebotomy therapy.

ID patients were defined as those with an SF of $<20 \mu \mathrm{g} / \mathrm{l}$. Average $\mathrm{Hb}$ in the ID group was $10.6 \mathrm{~g} / \mathrm{dl}$. With regard to the presence of anaemia in the ID group, six of eight females had a Hb level of $<11.5 \mathrm{~g} / \mathrm{dl}$ and the only male had a Hb level of $12 \mathrm{~g} / \mathrm{dl}$. All patients were undergoing endoscopy to evaluate causes of iron deficiency. Control patients were enrolled at the time of elective endoscopy for investigation of dyspeptic symptoms and had normal endoscopic findings, $\mathrm{Hb}$, and iron indices (that is, TS $25-56 \%$ and SF $20-330 \mu \mathrm{g} / \mathrm{l}$ ).

\section{Preparation of RNA}

Total RNA was extracted using the Qiagen RNeasy mini system (Qiagen Ltd). Prior to preparation of cDNA, the extracted RNA was treated with DNase 1, Amp grade (GibcoBrl, Paisley, UK) which digests single and double stranded DNA.

\section{Preparation of cDNA}

Reverse transcription of RNA was performed using standard reagent conditions. One microgram of DNase treated RNA with $4 \mu \mathrm{l}$ of $5 \times$ first strand buffer, $2 \mu \mathrm{l} 0.1 \mathrm{M}$ DTT (reducing agent), $1 \mu \mathrm{l} 10 \mathrm{mM}$ dNTPs, $1 \mu \mathrm{l}$ random primers (GibcoBrl), and $1 \mu \mathrm{l}$ (200 units) of Superscript II reverse transcriptase (GibcoBrl) were incubated at $25^{\circ} \mathrm{C}$ for 10 minutes, $42^{\circ} \mathrm{C}$ for 50 minutes, and finally $70^{\circ} \mathrm{C}$ for 15 minutes.

\section{Quantitative (real time) polymerase chain reaction} TaqMan real time polymerase chain reaction (PCR) primers and probes for quantification of DMTl and IREGl were purchased from Sigma-Genosys (Cambridgeshire, UK) and were used as previously described ${ }^{19}$ HFE real time primers and probes were designed using primer express software and did not differentiate between wild-type and mutated HFE. HFE primers used were forward -CCT TGT TTG AAG CTT TGG GC and reverse -CAC GGC GAC TCT CAT GAT CA, with the following TaqMan probe 5'-CGT GGA TGA CCA GCT GTT CGT GTT CT.

Using the Applied Biosystems 7700 Sequence Detector, real time quantification of DMTl, IREGl, and HFE was performed in cDNA samples from each individual included in the study. Amplification conditions were identical for analysis of all three molecules. Initial denaturation at $50^{\circ} \mathrm{C}$ for two minutes and then $95^{\circ} \mathrm{C}$ for 10 minutes was followed by 40 amplification cycles of $95^{\circ} \mathrm{C}$ for 15 seconds and $60^{\circ} \mathrm{C}$ for one minute.

All samples were analysed in duplicate and intrasample reproducibility was high. Mean results were normalised to the internal control $18 \mathrm{~S}$ ribosomal RNA to correct for imbalances in total mRNA content or unequal reverse transcription efficiency.

\section{DMT 1 immunohistochemistry}

Duodenal samples from five patients in each group were fixed in Carnoy's fluid and embedded in paraffin. Sections $(5 \mu \mathrm{m})$ were deparaffinised in xylene and blocked for endogenous peroxidase in 3\% hydrogen peroxide, prior to incubation with the purified anti-DMTl antiserum (kindly donated by Dr J Bastin), at a concentration of $0.03 \mathrm{mg} / \mathrm{ml}$ for 45 minutes at room temperature. Negative control slides omitted the primary antiserum. Visualisation of the antibody-antigen complex was carried out using the commercially available Vectastain ABC Elite kit (Vector Laboratories, Burlingame, California, USA) and detected using 0.05\% 3'3' diaminobenzidine tetrahydrochloride with $0.01 \%$ hydrogen peroxide. Slides were counterstained using methyl green. The intensity of DMTl staining was assessed by a single pathologist $\left(\mathrm{CO}^{\prime} \mathrm{K}\right)$ and scored as weak, moderate, or strong.

The study protocol was approved by the ethics committee of the Mater Misericordiae University Hospital and all participants gave written informed consent.

\section{Statistical analysis}

Statistical evaluation was carried out using SPSS for Windows (version 11). All patient characteristics are expressed as mean (SD). Duodenal levels of DMTI, IREGI, and HFE are expressed as a ratio of $18 \mathrm{~S}$ ribosomal RNA and reported as mean (SD). Results for SF and quantitative results of real time PCR for DMTI and IREGl showed skewed distributions and were transformed logarithmically for statistical evaluation. Comparison between patient groups was performed using independent sample $t$ tests. Correlations were done using the Spearman rank method.

\section{RESULTS}

\section{Clinical characteristics of patients}

The clinical characteristics of all individuals are presented in table 1. All ID patients were negative for the C282Y mutation but four were heterozygous for the H63D mutation. H63D heterozygotes do not accumulate iron and are phenotypically normal. ${ }^{29}{ }^{30}$ All control patients were negative for both C282Y and H63D mutations.

\begin{tabular}{|c|c|c|c|c|c|}
\hline Variable & $\begin{array}{l}\text { Total HH group } \\
(\mathrm{n}=33)\end{array}$ & $\begin{array}{l}\text { HH untreated } \\
(n=21)\end{array}$ & $\begin{array}{l}\text { HH treated* } \\
(n=12)\end{array}$ & $\begin{array}{l}\text { ID } \\
(n=9)\end{array}$ & $\begin{array}{l}\text { Controls } \\
(n=10)\end{array}$ \\
\hline No of patients (M/F) & $29 / 4$ & $20 / 1$ & $9 / 3$ & $1 / 8$ & $5 / 5$ \\
\hline Age at diagnosis (y) & $48(12)$ & 51 (11) & $44(13)$ & $52(10)$ & $43(17)$ \\
\hline $\mathrm{SF}(\mu \mathrm{g} / \mathrm{l})$ & $\begin{array}{l}1532(1318) \\
n=32\end{array}$ & 1804 (1523) & $114(90)$ & $7.7(5)$ & $94(85)$ \\
\hline TS (\%) & $\begin{array}{l}79(14) \\
n=29\end{array}$ & $\begin{array}{l}77(17) \\
n=18\end{array}$ & $66(23)$ & $20(13)$ & $31(10)$ \\
\hline $\mathrm{Hb}(\mathrm{g} / \mathrm{dll})$ & $\begin{array}{l}15(1.1) \\
n=32\end{array}$ & $15(1.0)$ & $14(1.0)$ & $10.6(2)$ & $14(1.7)$ \\
\hline
\end{tabular}

Values are mean (SD)

$\mathrm{HH}$, hereditary haemochromatosis; $\mathrm{HH}$ untreated, patients who had not yet undergone phlebotomy therapy; $\mathrm{HH}$ treated, patients who were iron depleted; ID, iron deficiency.

${ }^{*}$ Mean transferrin saturation (TS) and serum ferritin (SF) for this group prior to treatment were $81 \%$ (9) and $1011 \mu \mathrm{g} / \mathrm{l}$ (542), respectively. Results for SF were subsequently transformed logarithmically for statistical evaluation.

Normal laboratory values: SF 20-330 $\mu \mathrm{g} / \mathrm{l}$; TS 25-56\%; and haemoglobin ( $\mathrm{Hb}) 12.0-18.0 \mathrm{~g} / \mathrm{dl}$. 
Table 2 Real time polymerase chain reaction results for DMT-1, IREG1, and HFE in total $\mathrm{HH}$, treated $\mathrm{HH}$, untreated $\mathrm{HH}, \mathrm{ID}$, and control groups

\begin{tabular}{llllll}
\hline Variable & $\begin{array}{l}\text { Total HH group } \\
(\mathbf{n}=33)\end{array}$ & $\begin{array}{l}\text { HH untreated } \\
(\mathbf{n}=\mathbf{2 1})\end{array}$ & $\begin{array}{l}\text { HH treated } \\
(\mathbf{n}=12)\end{array}$ & $\begin{array}{l}\text { ID } \\
(\mathbf{n}=9)\end{array}$ & $\begin{array}{l}\text { Controls } \\
(\mathbf{n}=10)\end{array}$ \\
\hline DMT1 $^{*}$ & $0.98(1.7)$ & $0.44(0.9)$ & $1.9(2.3)$ & $4.0(5.4)$ & $0.3(0.3)$ \\
IREG1 $^{*}$ & $0.96(0.9)$ & $0.7(0.5)$ & $1.4(1.3)$ & $2.2(1.7)$ & $0.79(0.4)$ \\
HFE & $1.7(1.1) n=32$ & $1.5(1.0) n=20$ & $2.1(1.3)$ & $3.4(2.8)$ & $1.8(1.1)$ \\
\hline
\end{tabular}

Values are mean (SD).

DMT1, divalent metal transporter 1 ; IREGI, iron regulated gene $1 ; \mathrm{HH}$, hereditary haemochromatosis; $\mathrm{HH}$ untreated, patients who had not yet undergone phlebotomy therapy; $\mathrm{HH}$ treated, patients who were iron depleted; ID, iron deficiency.

*Results for DMT-1 and IREG1 were subsequently transformed logarithmically for statistical evaluation. Comparison of mean mRNA levels between cohorts revealed the following significant differences. For DMT1 mRNA: ID versus controls, $\mathrm{p}=0.018 ; \mathrm{HH}$ untreated versus $\mathrm{HH}$ treated, $\mathrm{p}=0.002 ; \mathrm{HH}$ treated versus controls, $p=0.006$. For IREGI mRNA: ID versus controls, $p=0.016$. No significant differences in HFE mRNA levels were observed between any of the cohorts.

\section{Quantitative real time PCR \\ DMT- 1}

Mean DMT-1 mRNA levels were significantly upregulated in the ID group relative to controls $(4.00 \vee 0.30 ; \mathrm{p}=0.018)$. Mean DMT mRNA levels were 3.2-fold higher in the total HH group compared with controls $(0.98 v 0.30)$ but this difference was not statistically significant (table 2 ). When the total $\mathrm{HH}$ group was divided into treated and untreated groups, significant differences were observed. DMT-1 levels were significantly increased in the treated group compared with the untreated group $(1.90 \vee 0.44 ; \mathrm{p}=0.002)$ (table 2$)$. Compared with controls, DMT-1 levels were significantly increased in the treated $(1.90 \vee 0.30 ; \mathrm{p}=0.006)$ but not in the untreated $(0.44 \vee 0.30 ; \mathrm{p}=0.7) \mathrm{HH}$ group. DMTl mRNA levels were not significantly different between treated $\mathrm{HH}$ (1.90) and ID patients (4.00) (fig 1).

DMT-1 levels did not correlate with SF, TS, or $\mathrm{Hb}$ in the ID group, in any of the HH groups, or in the control group. This study did not differentiate between IRE and non-IRE forms of DMTl but it has been shown that levels of the non-IRE form in duodenal tissue are extremely low and do not significantly contribute to the total DMTl level. ${ }^{20}$

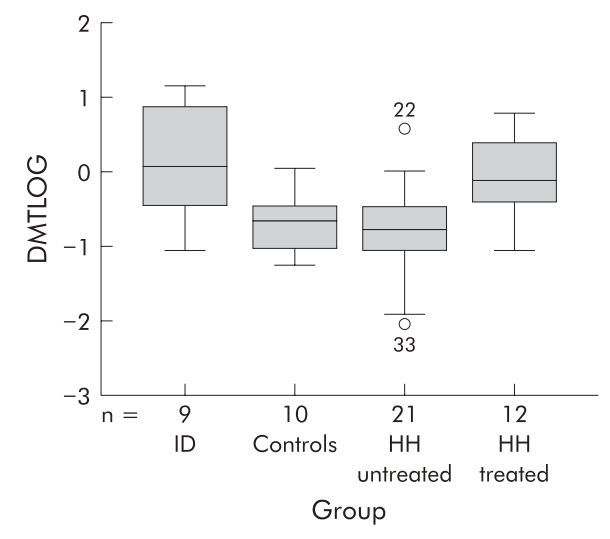

Figure 1 Divalent metal transporter 1 (DMT1) mRNA levels in duodenal biopsy specimens in untreated and treated hereditary haemochromatosis $(\mathrm{HH})$, iron deficiency (ID), and control groups. Values are DMT1/18S ribosomal RNA ratio in logarithmic scale, median (horizontal line), 75\% confidence interval (box), and minimal and maximal values (vertical line) in the respective patient groups. Extreme values are represented by $\mathrm{O}$. Comparison of mean DMT1 mRNA levels between cohorts revealed the following significant differences: ID versus controls, $p=0.018 ; \mathrm{HH}$ untreated versus $\mathrm{HH}$ treated, $\mathrm{p}=0.002 ; \mathrm{HH}$ treated versus controls, $p=0.006$.
IREG 1

Mean IREGl mRNA levels were significantly increased in the ID group relative to controls $(2.20 v 0.79 ; \mathrm{p}=0.016)$. IREG $\mathrm{l}$ mRNA levels were similar in the total $\mathrm{HH}$ group and the control group $(0.96 v 0.79 ; \mathrm{p}=0.8)$ (table 2$)$. When the $\mathrm{HH}$ group was further divided into the $\mathrm{HH}$ treated and untreated groups, mRNA levels were 1.8-fold greater in the treated group compared with the untreated group but this was not statistically significant ( $1.40 v 0.70 ; \mathrm{p}=0.1)$ (table 2$)$. Finally, compared with controls, IREGl mRNA levels were increased $(1.7$-fold $)$ in the treated group $(1.40 v 0.79 ; \mathrm{p}=0.5)$ but not in the untreated group $(0.70 v 0.79 ; \mathrm{p}=0.3)$ (fig 2).

IREG1 mRNA levels did not correlate with SF, TS, or $\mathrm{Hb}$ in the ID group or the HH groups. IREGl mRNA levels did however correlate with TS $(\mathrm{p}=0.028)$ and $\mathrm{Hb}(\mathrm{p}=0.003)$ but not with SF $(p=0.09)$ in the control group.

\section{HFE}

HFE mRNA levels were increased, although not significantly, in the ID group relative to the control group (3.40 $v 1.80$; $\mathrm{p}=0.1)$. In the total HH group, HFE mRNA levels were similar to those in the control group $(1.7 v 1.80 ; \mathrm{p}=0.9)$ (table 2). When the $\mathrm{HH}$ group was divided into $\mathrm{HH}$ treated and untreated groups, there was a 1.4-fold difference in mRNA levels between the treated and untreated groups but

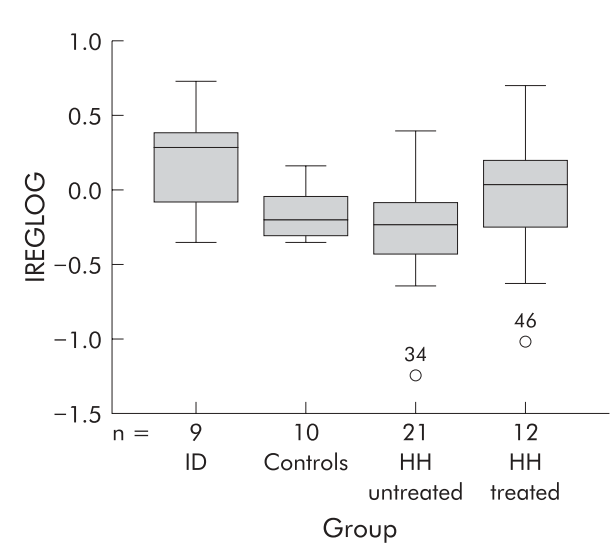

Figure 2 Iron regulated gene 1 (IREG1) mRNA levels in duodenal biopsy specimens in untreated and treated hereditary haemochromatosis $(\mathrm{HH})$, iron deficiency (ID), and control groups. Values are IREG/18S ribosomal RNA ratio in logarithmic scale, median (horizontal line), 75\% confidence interval (box), and minimal and maximal values (vertical line) in the respective patient groups. Extreme values are represented by $O$. Comparison of mean IREG1 mRNA levels between cohorts revealed a significant difference between ID and controls $(p=0.016)$. No other significant differences were observed. 


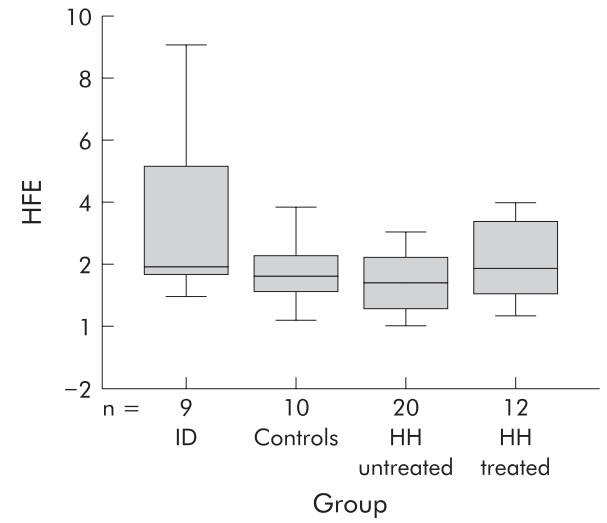

Figure 3 HFE mRNA levels in duodenal biopsy specimens in untreated and treated hereditary haemochromatosis $(\mathrm{HH})$, iron deficiency (ID), and control groups. Values are HFE/18S ribosomal RNA ratio, median (horizontal line), $75 \%$ confidence interval (box), and minimal and maximal values (vertical line) in the respective patient groups. No significant differences in HFE mRNA levels were observed between any of the cohorts.

this was not significant $(2.10 \vee 1.50 ; \mathrm{p}=0.1) \quad($ table 2$)$. Finally, there were no significant differences in HFE mRNA levels between the treated or untreated groups and the control group (fig 3). HFE levels did not correlate with SF, TS, or $\mathrm{Hb}$ in the ID group, the $\mathrm{HH}$ groups (with one exception, $\mathrm{HFE}$ correlated with $\mathrm{Hb}$ in the treated group; $\mathrm{p}<0.001$ ), or the control group.

\section{Immunohistochemistry}

Duodenal DMTl protein expression paralleled levels of mRNA in all cohorts. DMTl staining was most intense at the luminal surface of the duodenum. Average staining in $\mathrm{HH}$ treated, HH untreated, ID, and controls were moderate/ severe, mild, moderate/severe, and mild, respectively. No staining was seen in sections processed without antibody (fig 4).

\section{DISCUSSION}

In this study of Irish individuals, duodenal mRNA expression of DMT1, IREG1, and HFE was examined in a large cohort of untreated $\mathrm{HH}$ patients, phlebotomised (treated) HH patients, ID patients, and controls. In the untreated $\mathrm{HH}$ group, duodenal DMTl and IREGl mRNA expression were not significantly different from that seen in controls. In contrast, patients with phlebotomy treated $\mathrm{HH}$ had significantly increased DMTl (sixfold) and increased IREGl mRNA expression (1.8-fold) compared with the control cohort. ID patients had significantly increased levels of both DMT1 and IREG1 mRNA (13-fold and 2.8-fold, respectively) relative to controls. Duodenal DMT1 protein expression, as assessed by immunohistochemistry, paralleled levels of mRNA in all cohorts. Immunohistochemical analysis for IREGl was not carried out but its protein expression has been shown to closely reflect mRNA expression. ${ }^{19}$ HFE mRNA levels did not differ significantly from controls across any of the groups studied.

Results from studies examining duodenal DMTl and IREGl expression in untreated $\mathrm{HH}$ patients are inconsistent. ${ }^{19}{ }^{20}$ Zoller et al reported an 8-10-fold increase in DMT1 and a 2-5-fold increase in IREGl expression compared with normal controls. In contrast, Stuart et al have shown that DMTl and IREGl mRNA levels were similar to those observed in control subjects although untreated HH patients tended to have inappropriate expression of these transporters relative to their SF concentration. The reason for these inconsistencies in studies of untreated patients is not entirely clear but comparison of the patient cohort from the current study with those of Zoller et al and Stuart et al indicates that the untreated cohort investigated in our study (mean SF $1804 \mu \mathrm{g} / \mathrm{l}$ ) and the untreated cohort examined by Stuart et al
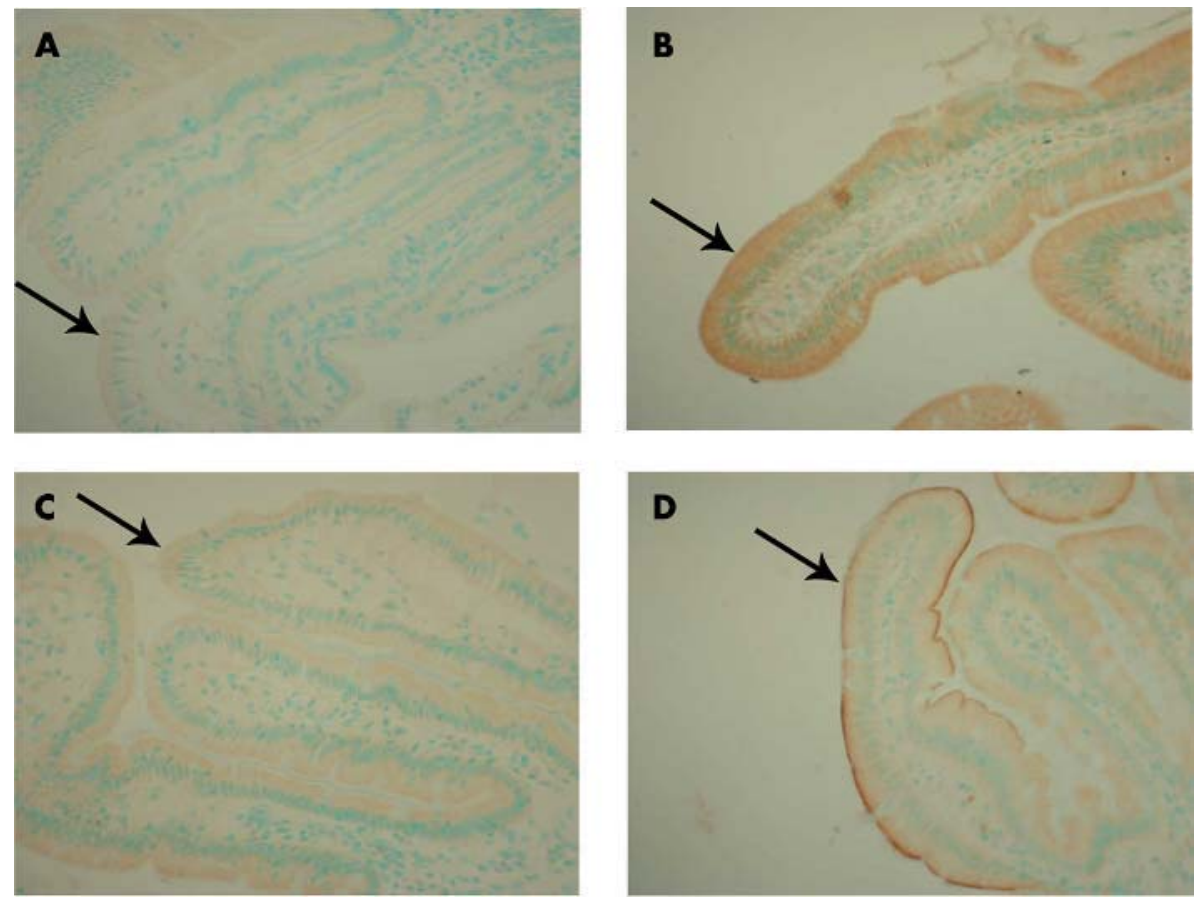

Figure 4 Immunohistochemical staining for divalent metal transporter 1 (DMT1) in duodenal biopsy specimens from control patients (A), patients with iron deficiency (ID), (B), untreated hereditary haemochromatosis (HH) (C), and treated HH patients (D). Immunostaining was most intense in the apical membrane in ID and treated $\mathrm{HH}$ patients compared with untreated and control duodenal tissue. 
(mean SF $900 \mu \mathrm{g} / \mathrm{l}$ ) carried a heavier body iron load compared with the Zoller et al untreated $\mathrm{HH}$ cohort (mean SF $642 \mu \mathrm{g} / \mathrm{l})$.

The duodenal enterocyte in HH patients behaves inappropriately relative to the degree of body iron overload. However, the level of expression of iron transporters within the enterocyte varies dependent on the influence of the putative stores and erythropoietic regulators. We suggest that $\mathrm{HH}$ patients initially load iron at rates equivalent to those observed in iron deficiency and when the body iron burden increases sufficiently, the putative stores regulator is stimulated (albeit at a set point inappropriate for the degree of body iron stores) to downregulate iron loading. Evidence supporting this proposal comes from a recent study describing age related iron loading effects in HFE knockout mice models. The study demonstrated that DMTl and IREGl expression were increased in young mice that were actively loading iron while older mice in whom hepatic iron loading persisted but did not progress had levels comparable with wild-type mice. ${ }^{31}$

It has long been thought that in patients with $\mathrm{HH}$, the duodenal enterocyte behaves as though the body were more iron deficient than it is. ${ }^{26}$ Evidence in support of this hypothesis has come from studies demonstrating increased transferrin receptor mRNA expression and low ferritin mRNA expression in duodenal enterocytes of patients with untreated HH. ${ }^{32}{ }^{33}$ Although our data demonstrate that the enterocyte in untreated $\mathrm{HH}$ patients does not appear to behave as being iron deficient as the iron transport expression profile in this cohort was comparable with controls rather than with ID, our findings do in fact indicate that the enterocyte is behaving as though the body were more iron deficient than it is. Untreated $\mathrm{HH}$ patients have levels of iron transporter expression that are similar to controls despite significantly higher body iron stores, and therefore since they cannot downregulate iron absorption to the same extent as healthy controls it may be assumed that this response is impaired. ${ }^{34-36}$ Treated $\mathrm{HH}$ patients have even higher levels of iron transporter expression equivalent to that seen in iron deficiency, despite normal iron stores. We propose that this enhanced iron transporter expression is secondary to the effect of the putative erythropoietic regulator. It is interesting to note that in both instances, the body is responding in the same way (that is, with inappropriately high iron transporter expression relative to body iron burden).

Recently, microarray analysis of duodenal iron transporter expression in HFE deficient mice also revealed an expression pattern largely consistent with iron overload and not iron deficiency. ${ }^{25}$ Similar levels of DMTl expression were found in wild-type mice, wild-type mice with secondary iron overload, and HFE deficient mice, although levels of Slc39la, the mouse orthologue of IREGl, were lower in HFE deficient mice. The authors speculate that this relative deficiency in IREGl may have a role in hepatic iron accumulation. We also found decreased IREGl expression in untreated HH patients compared with controls (although not significantly different) and observed a significant correlation between hepatic iron concentration in a small cohort of untreated $\mathrm{HH}$ patients $(n=5)$ with duodenal expression of IREGl and DMTl (unpublished observation), which may support a role for a deficiency in duodenal IREGl expression in hepatic iron accumulation.

While ID was found to result in a 13-fold increase in DMT1 expression versus normal controls, phlebotomy therapy also significantly affected DMTl expression, with a sixfold increase being found in phlebotomised $\mathrm{HH}$ patients compared with controls. This indicates that phlebotomy treatment not only induced increased iron absorption in $\mathrm{HH}$ patients, as evidenced by the increase in DMTl, but that these patients despite being homozygous for the C282Y HFE mutation retain the ability to respond to erythropoiesis induced through phlebotomy therapy.

Our findings have potential clinical implications. Current guidelines to maintain a serum ferritin level of less than $50 \mu \mathrm{g} / \mathrm{l}$ may represent a relative iron deficient state that ultimately results in increased rates of iron loading. ${ }^{37}$ Tolerating a maintenance SF at the upper physiological range may result in less demand for iron depletion in the long term. Furthermore, in those who have very mild expression of the disease with no evidence of end organ damage, initiation of iron depletion may ultimately precipitate more aggressive rates of iron accumulation. Clinical studies will be necessary to determine the potential benefit and safety of altering the current clinical guidelines.

Results obtained from studies examining the relationship between DMTl and serum ferritin are also inconsistent. ${ }^{16-20}$ In the present study, a significant inverse relationship between serum ferritin and iron transporter expression was not found for any of the cohorts examined. In contrast, some studies have demonstrated a significant inverse relationship between SF and DMTl expression in patients with HH, ID, and controls while others report an association in ID and controls only. ${ }^{16-20}$ These inconsistencies may arise from the fact that although SF is the best laboratory indicator of body iron load, its correlation with body iron load, as calculated by the amount of iron removed by phlebotomy (probably the most accurate method for measuring the iron burden in patients with iron storage disease), is not strong. ${ }^{38}$ It is also possible that the relationship between SF and DMT1 expression may not be linear across all values of SF and it is likely that other influences contribute to the relationship.

There is now growing support for the major site of HFE action being located in the liver, rather than the duodenum, and it has been proposed that HFE plays an important role in the regulation of hepatic hepcidin expression in response to changes in body iron stores. ${ }^{29}$ Evidence in support of the liver as the major site of HFE action has also recently been demonstrated in mouse models of $\mathrm{HH}$ where constitutive expression of hepcidin prevented iron overload in these animals $^{39}$ However, the mechanism whereby HFE senses body iron levels and brings about an appropriate hepcidin response has not yet being elucidated. ${ }^{40}$

Although the findings of this study do not provide conclusive evidence demonstrating that the major site of HFE action may not lie in the duodenum, HFE mRNA expression did not vary significantly across any of our cohorts and the lack of functional HFE did not prevent C282Y homozygous $\mathrm{HH}$ patients from responding to a relative state of ID induced by phlebotomy treatment through upregulation of DMT1. This latter observation is supported by iron absorption studies in HFE mutant mice where reduced iron stores or stimulated erythropoiesis induced by phlebotomy resulted in preservation of the ability to increase iron absorption to the same degree as wild-type animals. ${ }^{28}$

In conclusion, this study has demonstrated that duodenal DMTI and IREGl mRNA expression are not increased in patients with untreated $\mathrm{HH}$ relative to controls, which contrasts with findings in ID patients and treated $\mathrm{HH}$ patients who had increased levels of these molecules. Although levels in untreated $\mathrm{HH}$ patients were comparable with control patients, these levels were in fact inappropriately high relative to the body iron burden. Furthermore, phlebotomy treatment significantly increased expression of these transporters, indicating that phlebotomy induced erythropoiesis clearly affects iron absorption. Finally, DMTl and IREGl mRNA expression were significantly increased in patients with ID, indicating that these molecules are indeed 
important mediators in the response to decreased body iron stores.

\section{ACKNOWLEDGEMENTS}

This work was supported by grants from the Health Research Board of Ireland and the Mater College Foundation, Dublin, Ireland. The authors thank Dr Judy Bastin from the Institute of Molecular Medicine at the University of Oxford for her generous gift of the DMTl antiserum. Finally, the authors would also like to thank Catherine Moss at the Conway Institute, University College Dublin, for technical assistance with real time PCR.

\section{Authors' affiliations}

T Kelleher, E Ryan, S Barrett, M Sweeney, V Byrnes, J Crowe, Centre for Liver Disease, Mater Misericordiae University Hospital, Dublin, Ireland

C O'Keane, Department of Pathology, Mater Misericordiae University Hospital, Dublin, Ireland

\section{REFERENCES}

1 Trinder D, Fox C, Vautier G, et al. Molecular pathogenesis of iron overload. Gut 2002;51:290-5.

2 Fleming RE, Sly WS. Mechanisms of iron accumulation in hereditary haemochromatosis. Annu Rev Physiol 2002;64:663-80.

3 Finch C. Regulators of iron balance in humans. Blood 1994;84:1697-702.

4 Pietrangelo A. Physiology of iron transport and the haemochromatosis gene. Am J Physiol Gastrointest Liver Physiol 2002;282:G403-14.

5 Feder JN, Gnirke A, Thomas W, et al. A novel MHC class I-like gene is mutated in patients with hereditary haemochromatosis. Nat Genet 1996; 13:399-408.

6 Fleming RE, Sly WS. Hepcidin: a putative iron-regulatory hormone relevant to hereditary haemochromatosis and the anemia of chronic disease. Proc Nat Acad Sci U S A 2001;98:8160-2.

7 Gunshin H, Mackenzie B, Berger UV, et al. Cloning and characterization of a mammalian proton-coupled metal ion transporter. Nature 1997;388:482-8.

8 Fleming MD, Romano MA, Su MA, et al. Nramp2 is mutated in the anemic Belgrade (b) rat: evidence of a role for Nramp2 in endosomal iron transport. Proc Natl Acad Sci U S A 1998;95:1148-53.

9 Fleming MD, Trenor CC iii, Su MA, et al. Microcytic anaemia mice have a mutation in Nramp2, a candidate iron transporter gene. Nat Genet 1997; 16:383-6.

10 Donovan A, Brownlie A, Zhou Y, et al. Positional cloning of zebrafish ferroportin 1 identifies a conserved vertebrate iron exporter. Nature 2000;403:776-81.

11 McKie AT, Marciani P, Rolfs A, et al. A novel duodenal iron-regulated transporter, IREG1, implicated in the basolateral transfer of iron to the circulation. Mol Cell 2000;5:299-309.

12 Abboud S, Haile DJ. A novel mammalian iron-regulated protein involved in intracellular iron metabolism. J Biol Chem 2000;275:19906-12.

13 Nicolas G, Chauvet C, Viatte L, et al. The gene encoding the iron regulatory peptide hepcidin is regulated by anemia, hypoxia, and inflammation. J Clin Invest 2002;110:1037-44.

14 Nicolas G, Bennoun M, Devaux I, et al. Lack of hepcidin gene expression and severe tissue iron overload in upstream stimulatory factor 2 (USF2) knockout mice. Proc Natl Acad Sci U S A 2001;98:8780-5.

15 Frazer DM, Wilkins SJ, Becker EM, et al. Hepcidin expression inversely correlates with the expression of duodenal iron transporters and iron absorption in rats. Gastroenterology 2002;123:835-44

16 Zoller H, Pietrangelo A, Vogel W, et al. Duodenal metal-transporter (DMT1 Nramp-2) expression in patients with hereditary haemochromatosis. Lancet 1999;353:2120-3.
17 Rolfs A, Bonkovsky HL, Kohlroser JG, et al. Intestinal expression of genes involved in iron absorption in humans. Am J Physiol Gastrointest Liver Physiol 2002;282:G598-607.

18 Byrnes V, Barrett S, Ryan E, et al. Increased duodenal DMT1 expression and unchanged HFE mRNA levels in HFE associated hereditary haemochromatosis and iron deficiency. Blood Cells Mol Dis 2002;29:251-60.

19 Zoller H, Koch RO, Theurl I, et al. Expression of the duodenal iron transporters divalent-metal transporter 1 and ferroportin 1 in ID and iron overload. Gastroenterology 2001;120:1412-19.

20 Stuart KA, Anderson GJ, Frazer DM, et al. Duodenal expression of iron transporter molecules in untreated haemochromatosis subjects. Gut 2003;52:953-9.

21 Griffiths WJH, Sly WS, Cox TM. Intestinal iron uptake determined by divalent metal transporter is enhanced in HFE deficient mice with haemochromatosis. Gastroenterology 2001:120:1420-9.

22 Fleming RE, Migas $M$, Zhou XY, et al. Mechanism of increased iron absorption in murine model of hereditary haemochromatosis: increased duodenal expression of the iron transporter DMT1. Proc Natl Acad Sci U S A 1999:96:3143-8.

23 Dupic F, Fruchon S, Bensaid M, et al. Inactivation of the haemochromatosis gene differentially regulates duodenal expression of iron-related mRNAs between mouse strains. Gastroenterology 2002;122:745-51.

24 Cannone-Hergaux $\mathbf{F}$, Levy JE, Fleming MD, et al. Expression of the DMT (Nramp2/DCT1) iron transporter in mice with genetic iron overload disorders. Blood 2001;97:1138-40.

25 Muckenthaler M, Roy CN, Custodio AO, et al. Regulatory defects in liver and intestine implicate abnormal hepcidin and Cybrdl expression in mouse haemochromatosis. Nat Genet 2003;34:102-7.

26 Bomford A. Genetics of haemochromatosis. Lancet 2002;360:1673-81.

27 Brissot P. Milestones in liver disease: the discovery of the new haemochromatosis gene. J Hepatol 2003;38:704-9.

28 Ajioka RS, Levy JE, Andrews NC, et al. Regulation of iron absorption in $\mathrm{Hfe}$ mutant mice. Blood 2002;100:1465-9.

29 Bridle KR, Frazer DM, Wilkins SJ, et al. Disrupted hepcidin regulation in HFE associated haemochromatosis and the liver as a regulator of body iron homeostasis. Lancet 2003;361:669-73.

30 Jackson HA, Carter K, Darke C, et al. HFE mutations, iron deficiency and overload in 10,500 blood donors. Br J Haematol 2001;114:474-84.

31 Fleming RE, Ahmad KA, Ahmann JR, et al. Determinants of iron accumulation in the HFE knockout mouse model of hereditary haemochromatosis. Bioiron 2003. The International Bio-iron Society, World Congress on Iron Metabolism. NIH Bethesda, USA, 4-9 May 2003. Podium presentation 89.

32 Pietrangelo A, Rocchi E, Casalgrandi G, et al. Regulation of transferrin, transferrin receptor and ferritin genes in human duodenum. Gastroenterology 1992; 102:802-9

33 Lombard ML, Bomford AB, Polson RJ, et al. Differential expression of transferrin receptor in duodenal mucosa in iron overload:evidence for a site specific defect in genetic haemochromatosis. Gastroenterology 1990;98:976-84

34 Powell LW, Campbell CB, Wilson E. Intestinal mucosal uptake of iron and iron retention in idiopathic haemochromatosis as evidence for a mucosal abnormality. Gut 1970;11:727-31.

35 Lynch SR, Skikne BS, Cook JD. Food iron absorption in idiopathic haemochromatosis. Blood 1989;74:2187-93.

36 McLaren GD, Nathanson MH, Jacobs A, et al. Regulation of intestinal iron absorption and mucosal iron kinetics in hereditary haemochromatosis. J Lab Clin Med 1991;117:390-401.

37 Tavill S. Diagnosis and management of haemochromatosis. Hepatology $2001 ; 33: 1321-8$

38 Beutler E, Felitti V, Ho NJ, et al. Relationship of body iron stores to levels of serum ferritin, unsaturated iron binding capacity and transferrin saturation in patients with iron storage disease. Acta Haematol 2002;107:145-9.

39 Nicolas G, Viatte L, Lou D-Q, et al. Constitutive hepcidin expression prevents iron overload in a mouse model of hemochromatosis. Nat Genet 2003;34:97-101.

40 Frazer DM, Anderson GJ. The orchestration of body iron intake: how and where do enterocytes receive their cues. Blood Cells Mol Dis 2003;30:288-97 